\title{
Gamma-spectrometric measurement procedure for a clearance concept of radioactively contaminated mercury from nuclear facilities
}

\author{
Larissa Klaß ${ }^{1}$ (I) $\cdot$ Philipp Ritz ${ }^{1} \cdot$ Marius Hirsch $^{2} \cdot$ John Kettler $^{2} \cdot$ Andreas Havenith $^{2} \cdot$ Andreas Wilden $^{1}$ (D . \\ Giuseppe Modolo ${ }^{1}$ (1)
}

Received: 6 January 2021 / Accepted: 9 June 2021 / Published online: 24 June 2021

(C) The Author(s) 2021

\begin{abstract}
Radioactive mercury waste constitutes a significant challenge, as no approved disposal concept yet exists for such waste in Germany. This work describes a decontamination and measurement procedure for a possible clearance of mercury from nuclear facilities and release into reuse or conventional hazardous waste disposal to reduce the amount of mercury in a nuclear repository. The measurement setup and procedure were developed and evaluated including Monte-Carlo N-Particle ${ }^{\circledR}$ Transport Code $\left(M C N P{ }^{\circledR}\right.$ and Monte Carlo N-Particle ${ }^{\circledR}$ are registered trademarks owned by Los Alamos National Security, LLC, manager and operator of Los Alamos National Laboratory, (Werner 2018, Werner 2017)), simulations to ensure conservative assumptions during the measurements. Results from decontaminated mercury samples show that a clearance pursuant to the German regulations would be feasible.
\end{abstract}

Keywords Radioactive mercury · Decontamination · Clearance measurements · MCNP® $\cdot$ Gamma spectrometry

\section{Introduction}

During the decommissioning of nuclear facilities, different "problematic" nuclear waste streams can occur for which no disposal path has yet been developed. This includes waste with a high chemical toxicity and/or a high mobility in the environment (e.g. a high solubility), for example toxic metals like beryllium, cadmium or mercury, that cannot be disposed of (directly) in a nuclear repository [3-7].

No approved disposal concept for contaminated mercury waste from nuclear facilities yet exists in Germany because the disposal comprises significant problems. The high toxicity and mobility of most mercury compounds, for example, leads to a limited acceptance of radioactive mercury waste in "Schacht Konrad", the German repository for nuclear waste with negligible heat generation, due to groundwater

Giuseppe Modolo g.modolo@fz-juelich.de

1 Forschungszentrum Jülich GmbH, Institut Für EnergieUnd Klimaforschung - Nukleare Entsorgung Und Reaktorsicherheit (IEK-6), Wilhelm-Johnen Straße 1, 52425 Jülich, Germany

2 Aachen Institute for Nuclear Training GmbH, Cockerillstraße 100, 52222 Stolberg (Rhld.), Germany regulations $[8,9]$. Furthermore, the liquid state of elemental mercury precludes a direct disposal but requires a prior solidification before disposal in the nuclear repository. An approved disposal concept for larger amounts of mercury waste from nuclear facilities in Germany has not yet been reported [3, 4].

Mercury has been applied in different nuclear facilities all around the world, e.g. as cooling and shielding material, as it offers several advantages being the only liquid metal at room temperature and having a very high density that causes good shielding properties. Despite these promising properties, little to no information can be found about the disposal of historic radioactive mercury wastes or about specific future disposal concepts for radioactive mercury wastes. Most current literature about mercury focuses on mercury in the environment and on environmental applications, especially measurement and decontamination, e.g. of mercury-contaminated soils or waters [10-14].

In the 1950's mercury was applied as cooling medium in the "Clementine" reactor, the first fast neutron reactor in Los Alamos National Laboratory, New Mexico, and was contaminated with different radionuclides, e.g. plutonium, during reactor operation. Mercury was also used as coolant in the BR-I / BR-II fast breeder reactors in the former Soviet Union. Liquid sodium then soon replaced mercury as 
primary coolant for the next generation of fast reactor types and no detailed information is available about the mercury disposal after the dismantling of the reactors [15-18].

Another large-scale application of mercury is its use in different separation processes, e.g. as a solvent for the separation of uranium from used nuclear fuel elements in the HERMEX process. Uranium is dissolved in mercury during this process forming an amalgam that is then separated from other impurities and the mercury can afterwards be removed thermally. The exact amount of mercury that has been used in this process and the resulting amount of radioactive mercury waste is not known [19, 20]. Smaller applications generally included the use of mercury as sealing and shielding material in different nuclear facilities, some of which are still in use, in decommissioning or dismantling [3]. Mercury was used in rotating shielding plugs in the Prototype Fast Reactor (PFR), for example, and in the Dounreay Fast Reactor (DFR) in Scotland [21].

Nowadays the use of mercury in nuclear facilities is mainly still of interest for nuclear fusion and spallation facilities. It is used in the separation of ${ }^{6} \mathrm{Li}$ from ${ }^{7} \mathrm{Li}$, the former of which is essential for nuclear fusion applications in the production of tritium [3, 22-24]. In nuclear fusion mercury is also highly suitable as working fluid in the pumping of tritium. These pumps require a pumping fluid without any hydrogen atoms, thus excluding the application of most materials except metallic and ceramic ones [25-27].

In spallation sources, mercury is advantageous as target material due to its liquid state. A liquid material can easily be mixed and thus ensures a good heat distribution, while at the same time an embrittlement of the target material (as in solid materials) is avoided. Mercury is thus used in spallation targets in the Japan Spallation Neutron Source (JSNS), Tōkai, Japan, and in the Spallation Neutron Source (SNS), Oak Ridge, Tennessee [28-35]. To the best of our knowledge, no final disposal route for the mercury from this process has been approved.

In Germany, mercury-containing radioactive wastes are mainly expected from research facilities, the exact amount however is unclear. A smaller experimental spallation facility was installed at the Cooler Synchrotron (COSY), the Jülich Experimental Spallation target Set-up in COSY Area (JESSICA) facility in Jülich that contains about $470 \mathrm{~kg}$ of elemental mercury [36-38]. Simulations have been performed to determine possible activation products that could be formed in this spallation target and lead to a variety of different radionuclides, including, next to radioactive isotopes of platinum, gold, iodine, etc., the formation of radioactive mercury isotopes that could not be separated from the bulk of the elemental mercury in the target. This formation of radionuclides that cannot be separated from the mercury leads to the possibility that the whole mercury from this facility needs to be disposed of as radioactive waste as a decontamination of the mercury might not be possible [31-33].

In Jülich, about $600 \mathrm{~kg}$ of mercury were further used as shielding material in a hot cell facility and were contaminated with different (radioactive) materials. This mercury was removed and collected during decommissioning of the hot cell facility. At the moment there is no disposal path and therefore different options are discussed. Some radioactively contaminated mercury samples originating from this facility have been examined to develop a possible disposal concept $[4,6,39]$. Further mercury-containing wastes from nuclear facilities in Germany are expected, most of them with comparably small volumes. However, these wastes still have to be dealt with.

Such a disposal concept first foresees the decontamination of elemental mercury (e.g. by vacuum distillation and washing) and then a possible clearance of large parts of this material-with the possibilities of reuse or conventional hazardous waste disposal-according to the German radiation protection ordinance [40]. The amount of mercury waste that needs to be disposed of in a deep geological repository for radioactive waste would be minimised with this concept.

To the best of our knowledge, there is no literature available describing the radiological measurement and a setup or procedure for decontamination and clearance of mercury from nuclear applications. The radiological characterisation/ measurement of radioactive mercury is challenging due to the high density $\left(13.5 \mathrm{~kg} \mathrm{~L}^{-1}\right)$ and shielding effects of mercury. Furthermore, radioactive contamination might be distributed inhomogeneously in the mercury and a direct activity determination by gamma spectrometry is not possible due to the lack of an adequate efficiency calibration for radioactive mercury samples. The gamma-spectrometric measurement setup is thus simulated with MCNP ${ }^{\circledR}$ to determine the photo peak efficiencies for the measurement of radioactively contaminated mercury samples under conservative assumptions. Such conservative conditions are mandatory for possible clearance measurements to preclude an underestimation of the activity in the sample. This concept is described here including results from the measurements of real decontaminated mercury samples and evaluating the possibility of their clearance $[6,39]$. In a first step, contaminated mercury samples were radiologically characterised using a new wetchemical characterisation approach. The decontamination of contaminated mercury is demonstrated by vacuum distillation or washing, e.g. with nitric acid, and was found to be suitable for the waste from Jülich. This approach is briefly described here and the possibility of a clearance for such decontaminated mercury samples with the developed gamma-spectrometric measurement procedure is assessed.

To our knowledge, while there are several (historic and current) applications for mercury in nuclear facilities, there is no comparable study on the decontamination and 

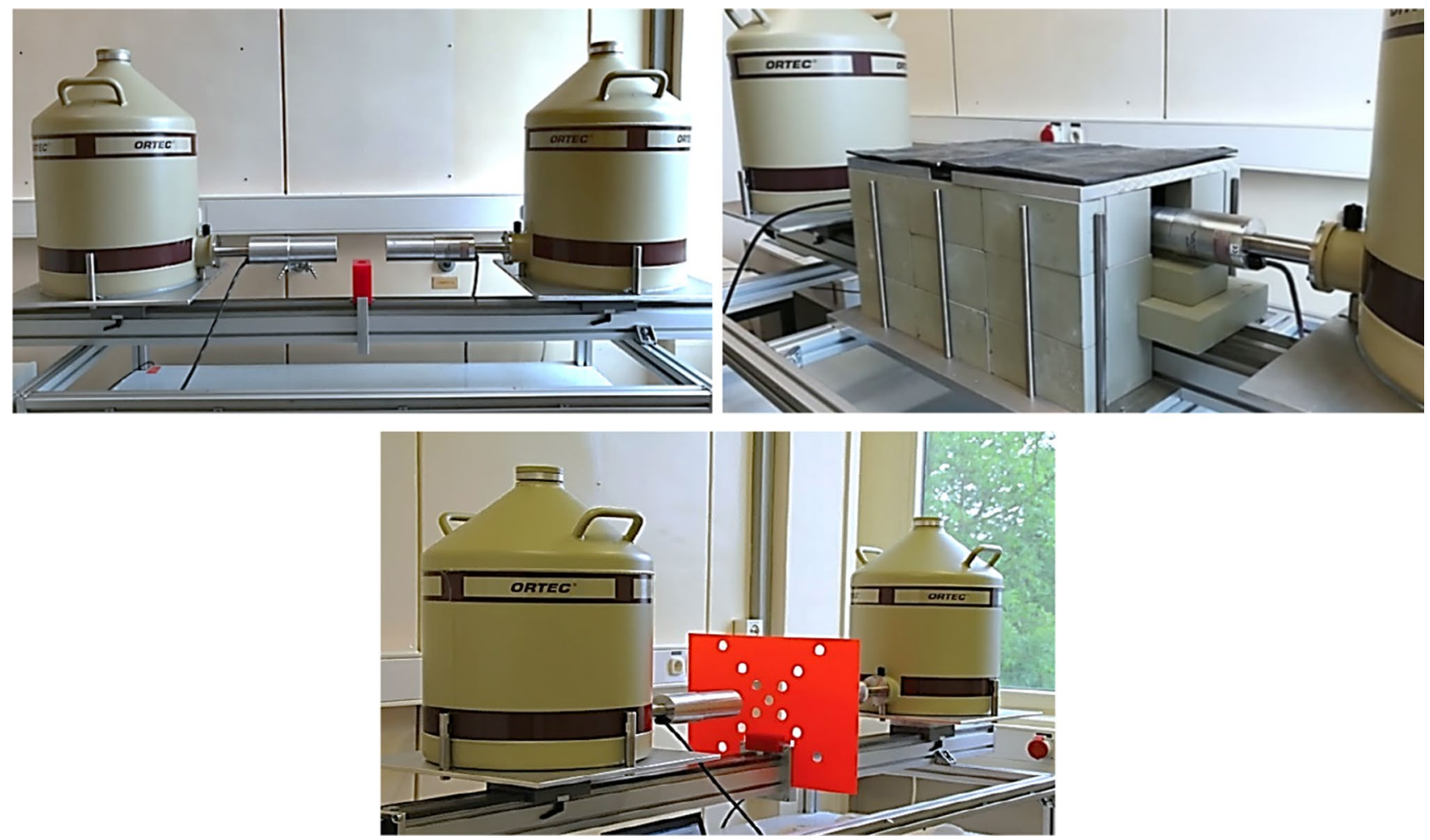

Fig. 1 Top left: HPGe detector setup without shielding, Top right: detector setup with lead shielding to reduce background radiation, Bottom: setup for measurement of point sources at different angles from the detectors

radiological measurement of mercury from nuclear applications. We have therefore developed a comprehensive concept for radiological measurements of mercury, its decontamination and potential clearance applying established modelling tools. While the method for efficiency calibration might be similar to other works, this work combines the theoretical approach with the practical applicability of decontamination and measurement of different waste samples from Jülich. This manuscript therefore shows that the combination of wet-chemical radiological characterisation and decontamination followed by gamma-spectrometric measurement allows a clearance of large parts of these radioactively contaminated mercury wastes. Especially the measurement of radioactive contaminations in elemental mercury poses a challenge in wet-chemical radiological characterisation as well as in non-destructive clearance measurements, that can be solved with our approach.

\section{Experimental}

The gamma-spectrometric setup used for decision-making measurements to evaluate the possibility of a clearance consisted of two coaxial semi-planar P-type HPGe detectors from Ortec $\AA^{\circledR}$ Ametek ${ }^{\circledR} \mathrm{GmbH}$ (Meerbusch, Germany) with relative efficiencies of $22 \%$ (detector 1 ) and $25 \%$ (detector 2). The detectors were mounted on a slide facing each other so that a sample could be placed in between and measured from opposite sides to increase the sensitivity of the measurement and to detect potential inhomogeneous activity distribution by comparison of the two simultaneous measurements (Fig. 1). The detectors were carefully aligned along the z-axis and fixed in their positions on the slide. The detectors were positioned within $\pm 0.1 \mathrm{~mm}$ from the indicated positions. The distance between both detectors can be varied by moving the detectors on the slide 


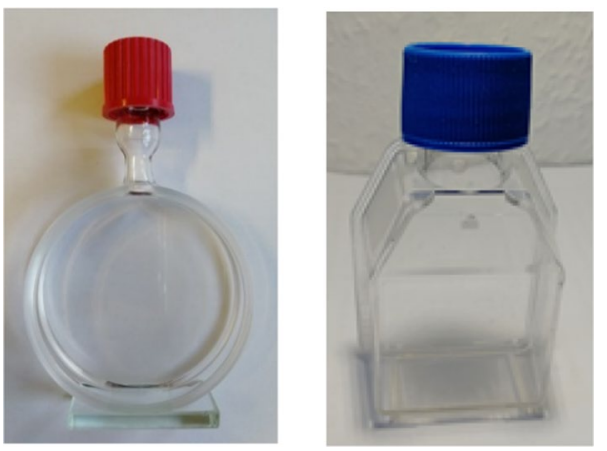

Fig. 2 Flasks for the measurement of decontaminated mercury samples, left: geometry-optimised cylindrical sample flask, right: commercially available cell culture flask

simultaneously in opposite directions. Measured spectra were evaluated by GammaVision version 5.20 and LabVision (LVis) version 1.0.

Point sources $\left({ }^{152} \mathrm{Eu},{ }^{241} \mathrm{Am},{ }^{60} \mathrm{Co},{ }^{137+} \mathrm{Cs}^{1}\right)$ used to evaluate the MCNP® detector models were all purchased from Amersham plc., Amersham, Great Britain. Point sources were measured at different distances from the detectors (5, $10,20,25$ and $40 \mathrm{~cm})$ and at different angles $\left(0^{\circ}, 15^{\circ}, 30^{\circ}\right.$, $45^{\circ}$, compare Fig. 1) to evaluate the quality of the MCNP® detector model. Two different sample flasks were used for the measurement of mercury samples and are compared in this work: an in-house custom-made cylindrical glass flask with an optimised geometry (Fig. 2 left) as well as a commercially available polystyrene cell culture flask (cell culture flask from Falcon ${ }^{\circledR}$ with a nominal volume of $25 \mathrm{~mL}$, Fig. 2 right). The cylindrical flask had an inner diameter of $5.56 \mathrm{~cm}$, a sample thickness of $1.01 \mathrm{~cm}$ and a volume of $24.5 \mathrm{~mL}$. The irregularly shaped cell culture flask had a sample thickness of $2.16 \mathrm{~cm}$, comprising an average sample volume of $25 \mathrm{~mL}$ and a maximum volume of $30 \mathrm{~mL}$.

For decision-making measurements for clearance both flasks were filled with decontaminated mercury samples and measured at a distance $d$ between each detector and the middle of the sample of $d=5 \mathrm{~cm}$. The measurement time was varied for different measurements. Dead time correction was performed automatically by the measurement software.

\footnotetext{
${ }^{1}$ The use of the + sign, e.g. in ${ }^{137+} \mathrm{Cs}$, follows the nomenclature used in the German Radiation Protection Ordinance. [40] The + character on the mother nuclide indicates that the exposition from the daughter nuclides listed in table 2 of the German radiation protection ordinance is included in the clearance values of the mother nuclides. For ${ }^{137+} \mathrm{Cs}$ for example, this includes the daughter nuclide ${ }^{137 \mathrm{~m}} \mathrm{Ba}$ (which is responsible for the emission at $661.67 \mathrm{keV}$ that is mainly evaluated in the context of this work), for ${ }^{90+} \mathrm{Sr}$ it includes the daughter ${ }^{90} \mathrm{Y}$. As the assessment of a possible clearance is based on the regulations from the German radiation protection ordinance, the nomenclature was followed throughout this manuscript.
}

Dead times were below 3\% for all measurements, and significantly below $1 \%$ for all measurements of samples that were considered for a clearance procedure.

Only the net peak area of the $661.67 \mathrm{keV}$ emission line of ${ }^{137+} \mathrm{Cs}$ was evaluated for the gamma-spectrometric activity determination in the measurement of the mercury samples. In prior radiochemical analyses, ${ }^{137+} \mathrm{Cs}$ had been determined as the main radionuclide in the samples as discussed in the following chapter. As the $661.67 \mathrm{keV}$ emission line shows a comparably high photo peak efficiency even inside the mercury matrix, ${ }^{137+} \mathrm{Cs}$ was used here as reference nuclide. The activities of the other radionuclides were determined according to their relative share in the samples as determined experimentally (see chapter "Characterisation and decontamination of mercury samples").

Decision threshold (allowing a conclusion whether the nuclide is present in the sample) and detection limit (the smallest amount of the nuclide that can be quantified) of the measurements were determined according to DIN ISO 11929 [41]. The sum formula for clearance was calculated as $\sum\left(\mathrm{C}_{\mathrm{i}} / \mathrm{FG}_{\mathrm{i}}\right)$ with $\mathrm{C}_{\mathrm{i}}$ as the activity of a nuclide in the sample and $\mathrm{FG}_{\mathrm{i}}$ as the clearance value for the respective nuclide given in the German radiation protection ordinance [40].

A commercially available TRU resin from Triskem was used for the radiochemical separation of the mercury-containing residues. The TRU column was first conditioned with $5 \mathrm{~mL}$ of $4 \mathrm{~mol} \mathrm{~L}^{-1}$ nitric acid. The column was then loaded with $5 \mathrm{~mL}$ of the dissolved mercury aliquot in $4 \mathrm{~mol} \mathrm{~L}^{-1}$ nitric acid. Afterwards, the column was eluted with different solvents: 4 mol L ${ }^{-1}$ nitric acid $(5 \mathrm{~mL}), 4 \mathrm{~mol} \mathrm{~L}^{-1}$ hydrochloric acid $(10 \mathrm{~mL})$ and $0.1 \mathrm{~mol} \mathrm{~L}^{-1}$ oxalic acid $(10 \mathrm{~mL})$. Different fractions were collected after elution from the column. The $5 \mathrm{~mL}$ from the conditioning of the column were discarded. Afterwards, the following fractions were collected: $3 \times 5 \mathrm{~mL}, 10 \times 1 \mathrm{~mL}$ and $1 \times 5 \mathrm{~mL}$. All fractions were analysed by inductively coupled plasma - mass spectrometry (ICP-MS) for mercury content, by alpha and gamma spectrometry and liquid scintillation counting (LSC).

\section{Results and discussion}

\section{Measurement setup and procedure for a clearance concept}

The gamma-spectrometric measurement concept was developed for potential clearance measurements of mercury samples from nuclear facilities. It is based on the measurement of ${ }^{137+} \mathrm{Cs}$ as a reference nuclide with a relatively high photo peak efficiency inside the mercury matrix.

It was not possible to determine an experimental photo peak efficiency calibration for the measurement of mercury samples, due to the high density of mercury and de-mixing 
Fig. $3 \mathrm{MCNP}{ }^{\circledR}$ model of the detector setup (geometric dimensions see Table 1)

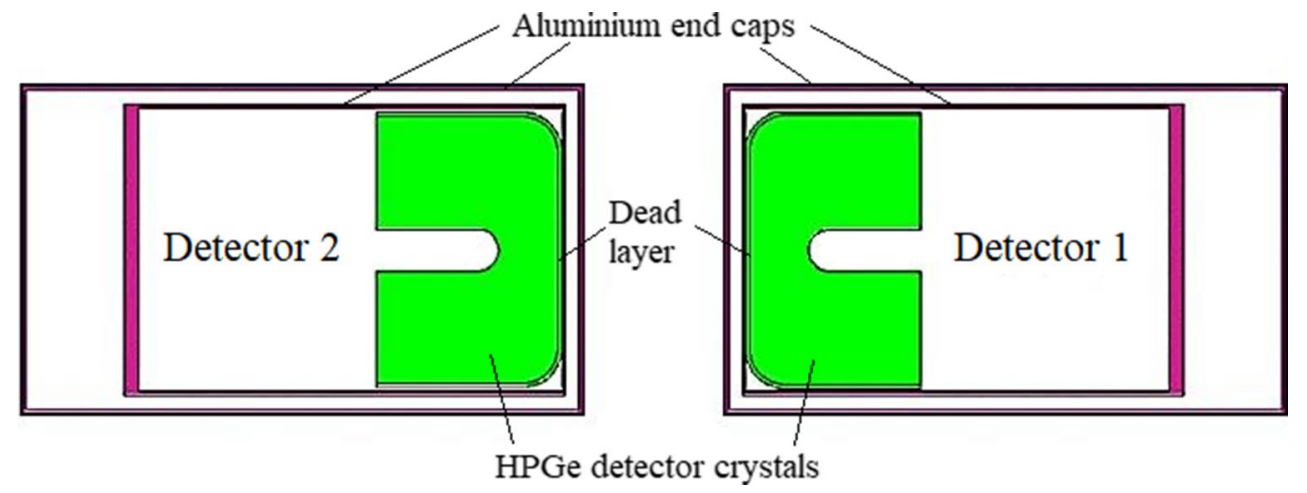

\begin{tabular}{lllllc}
\hline & \multicolumn{2}{l}{ Detector $2\left(\varepsilon_{\mathrm{r}}=25 \%\right)$} & & \multicolumn{2}{l}{ Detector 1 $\left(\varepsilon_{\mathrm{r}}=22 \%\right)$} \\
\cline { 2 - 3 } \cline { 5 - 6 } $\begin{array}{l}\text { Before valida- } \\
\text { tion }\end{array}$ & After validation & & $\begin{array}{l}\text { Before valida- } \\
\text { tion }\end{array}$ & After validation \\
\hline Crystal diameter $(\mathrm{mm})$ & 58.5 & 56.0 & 59.0 & 59.0 \\
Crystal length $(\mathrm{mm})$ & 39.6 & 39.6 & & 37.4 & 36.0 \\
Dead layer $(\mathrm{mm})$ & 0.7 & 0.4 & & 0.7 & 1.0 \\
\hline
\end{tabular}

Table 1 Geometric dimensions of the MCNP® detector models before and after experimental validation and adaption
The detector model was experimentally evaluated by measuring point sources of ${ }^{152} \mathrm{Eu},{ }^{241} \mathrm{Am},{ }^{60} \mathrm{Co}$ and ${ }^{137+} \mathrm{Cs}$ at different angles $\left(0,15,30,45^{\circ}\right)$ and distances $(5,10,20$, $25,40 \mathrm{~cm}$ ) to the detectors and comparison of the photo peak efficiencies of the measured spectra with the corresponding simulation results (all results of this comparison are included in the Supplementary Information, SI). Then the detector model was optimised to ensure as realistic as possible but still conservative conditions in the following activity determinations. For such, the simulated photo peak efficiency must be smaller than the real photo peak efficiency, i.e. the following condition must be met:

$$
\varepsilon_{\text {model }} / \varepsilon_{\text {measurement }}<1 \text {. }
$$

This $\varepsilon_{\text {model }} / \varepsilon_{\text {measurement }}$ ratio was determined for the measurement of the different point sources with different emission energies at different distances and angles (cf. SI). It was found to be partly above one and thus too high and could result in an underestimation of the sample activity, which has to be avoided. Furthermore, the results showed an energy dependency of the $\varepsilon_{\text {model }} / \varepsilon_{\text {measurement }}$ ratio, probably caused by some deviation of the crystal size and dead layer thickness between model and detectors.

The geometric specifications of the detectors were adapted to fulfill the condition $\varepsilon_{\text {model }} / \varepsilon_{\text {measurement }}<1$, by systematic variation of crystal size and dead layer thickness of both detector models. The results of these adaptions are summarised in Table 1 (the resulting values for the $\varepsilon_{\text {model }} /$ $\varepsilon_{\text {measurement }}$ ratio are included in the SI). The model was optimised for a distance $d$ of the detectors to the middle of the sample of $5 \mathrm{~cm}$ and the adaptions resulted in a reduction of the simulated active detector volume by $5.7 \%$ for detector 1 aluminium end caps. 

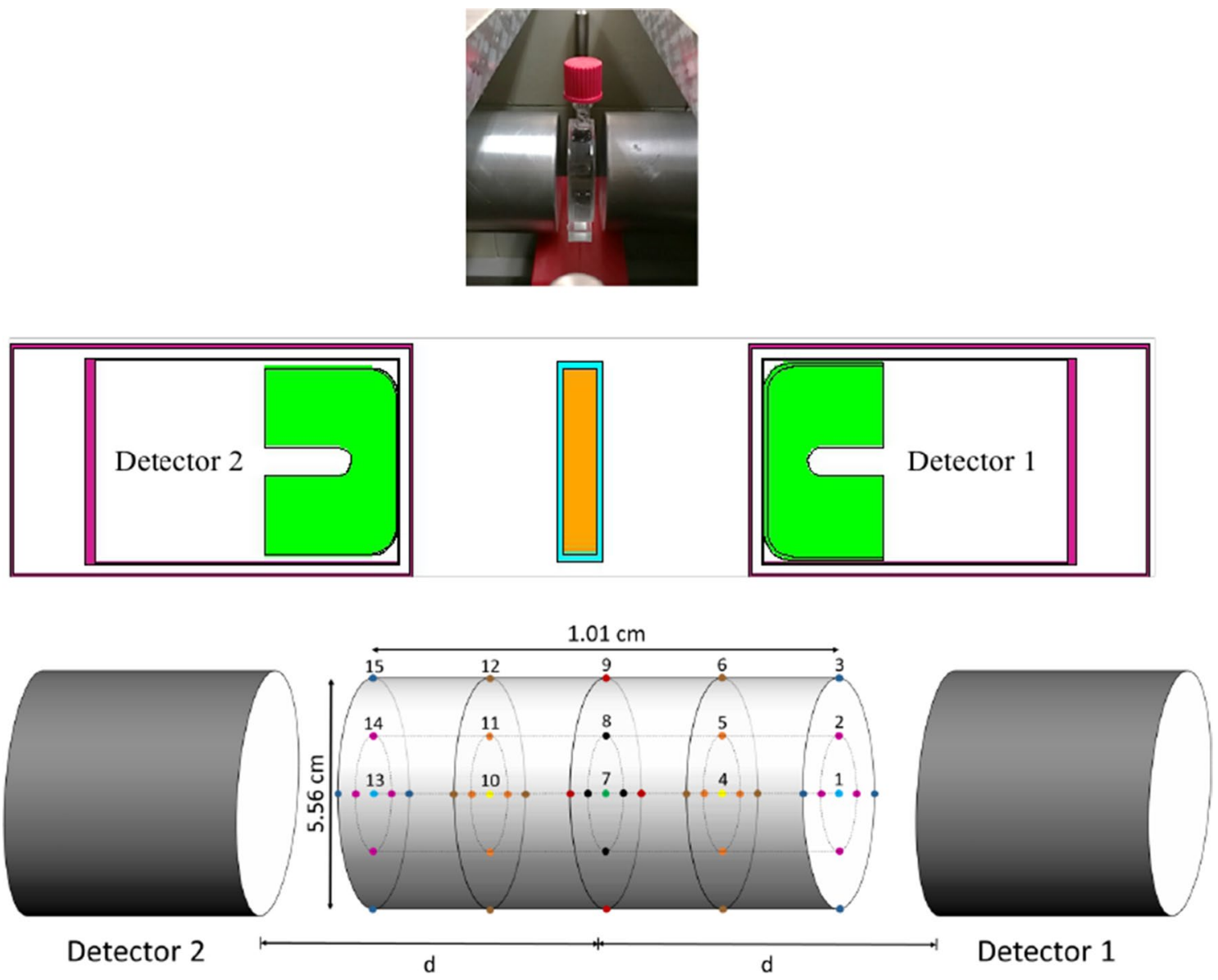

Fig. 4 Top: Photo of the cylindrical sample flask placed between both HPGe detectors, middle: MCNP® model of the cylindrical sample flask between both HPGe detectors, bottom: positions of a point

and by $6.5 \%$ for detector 2 . These adapted MCNP® detector models were used for calculation of the conservative photopeak efficiencies in the gamma spectrometric measurements.

\section{Determination of photo peak efficiencies for different geometries}

After the validation and optimisation of the MCNP® detector model, the photo peak efficiency in a mercury sample was determined. For a conservative activity estimation in clearance measurements, the point of the lowest photo peak efficiency of an infinitesimal point source in the mercury matrix must be known. Therefore, a series of MCNP® simulations was performed to determine this point for both sample flasks.

The cylindrical sample flask filled with $24.5 \mathrm{~mL}$ mercury was simulated with a distance $d$ from the middle of the sample to each detector of $5 \mathrm{~cm}$. A ${ }^{137+} \mathrm{Cs}$ point source was simulated at 15 different positions inside this mercury-filled source simulated in the mercury matrix in the cylindrical sample flask. The dimensions are not to scale, the flask was broadened for a better visibility

sample flask. The positions of the simulated point source are shown in Fig. 4.

The simulated photo peak efficiencies of the $661.67 \mathrm{keV}$ emission line of ${ }^{137+} \mathrm{Cs}$ at the different positions in the mercury sample are illustrated in Fig. 5 and are summarised in Table 2. For the measurement with just a single detector, the highest photo peak efficiency is detected in front of the detector-at position 1 for the measurement with detetor 1 and at position 13 for the measurement with detector 2 . The lowest efficiency is detected at the respective opposite side of each detector, at the outer periphery of the sample due to the larger distance to the detector and shielding caused by the mercury matrix (at position 15 for detector 1 and position 3 for detector 2). The efficiencies of detector 2 are generally higher than for detector 1 due to its higher relative efficiency. For the sum spectrum of both detectors, the point of lowest photo peak efficiency was found in the middle between the detectors at the outer periphery of the mercury sample (position 9). The simulated value of $6.07 \cdot 10^{-3}$ at that position was used for conservative activity determination in 


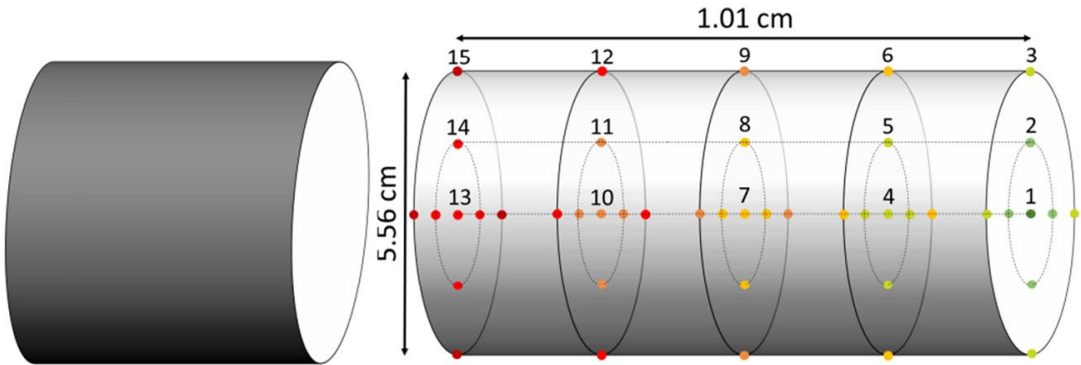

Detector 2

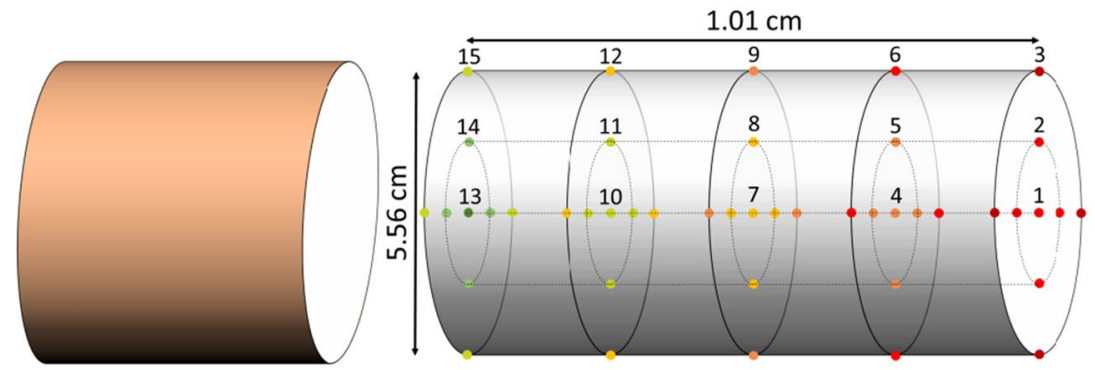

Detector 2

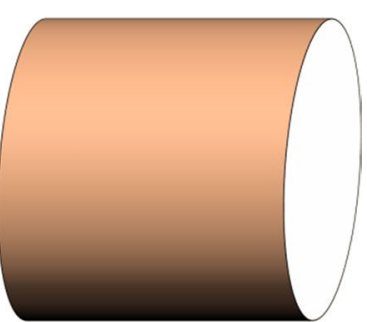

Detector 1

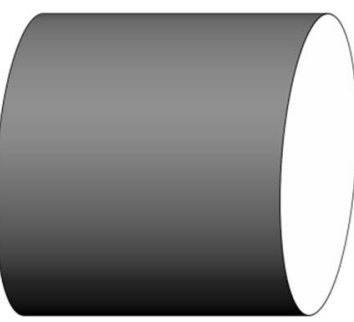

Detector 1
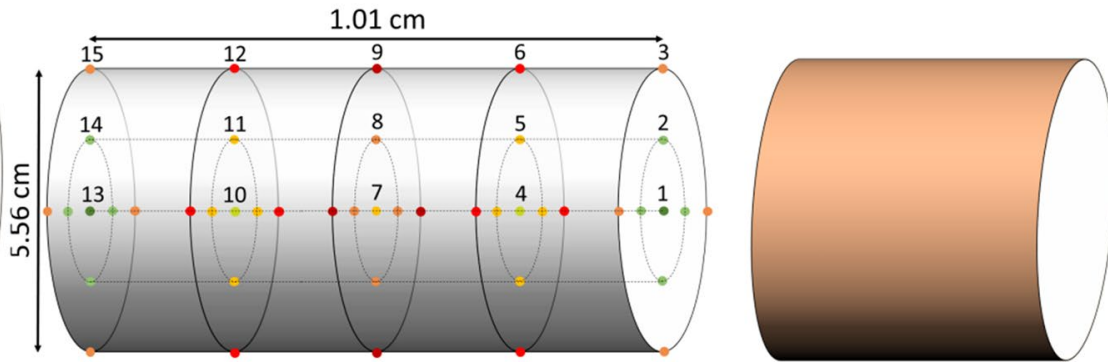

Detector 1

Detector 2 d d

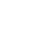

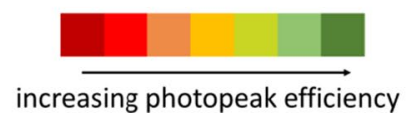

Fig. 5 Simulated photo peak efficiencies at different positions inside the mercury-filled cylindrical sample flask, top: results for detector 1 only, middle: results for detector 2 only, bottom: results for the simultaneous measurement with both detectors

Table 2 Highest and lowest simulated photo peak efficiencies determined for the $661.67 \mathrm{keV}^{137+} \mathrm{Cs}$ emission line in the cylindrical sample flask filled with mercury

\begin{tabular}{lcll}
\hline & Position & Photo peak efficiency & MCNP Uncertainty* \\
\hline Highest value for detector 1 & 1 & $8.55 \cdot 10^{-3}$ & $9.41 \cdot 10^{-6}$ \\
Highest value for detector 2 & 13 & $8.87 \cdot 10^{-3}$ & $9.76 \cdot 10^{-6}$ \\
Lowest value for detector 1 & 15 & $1.27 \cdot 10^{-3}$ & $3.55 \cdot 10^{-6}$ \\
Lowest value for detector 2 & 3 & $1.32 \cdot 10^{-3}$ & $3.68 \cdot 10^{-6}$ \\
Highest values for sum spectrum & 13 & $1.04 \cdot 10^{-2}$ & $1.04 \cdot 10^{-5}$ \\
& 1 & $1.02 \cdot 10^{-2}$ & $1.02 \cdot 10^{-5}$ \\
Lowest value for sum spectrum & 9 & $6.07 \cdot 10^{-3}$ & $7.89 \cdot 10^{-6}$ \\
\hline
\end{tabular}

*This is the statistical uncertainty calculated by MCNP 


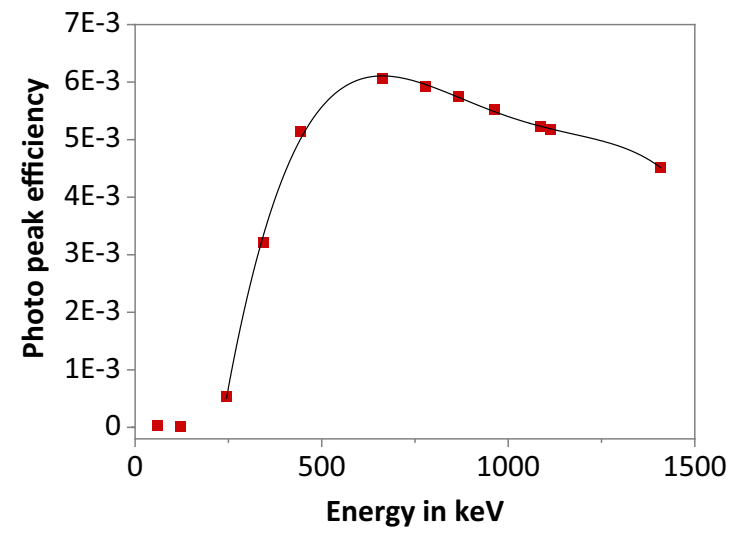

Fig. 6 Simulated photo peak efficiency curves for the sum spectrum at the point of the lowest photo peak efficiency determined for the $661.67 \mathrm{keV}$ emission line in the cylindrical sample flask, left: effi-

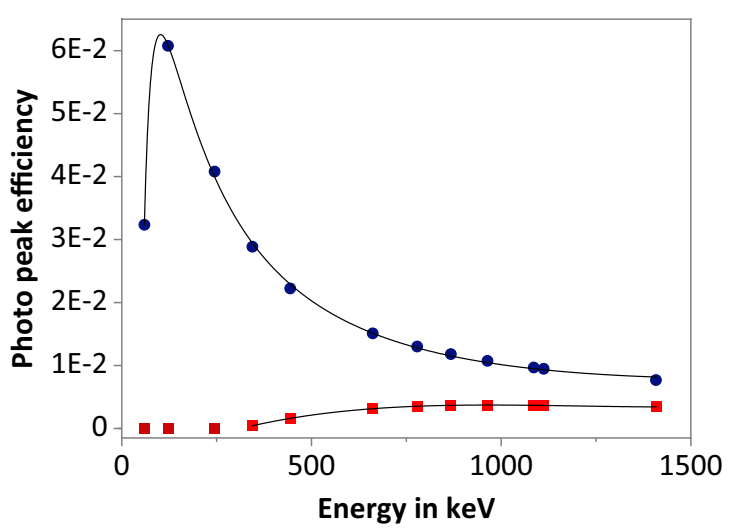

ciency curve in mercury matrix (red squares), right: comparison of the efficiency curves in mercury (red squares) and air (blue circles)

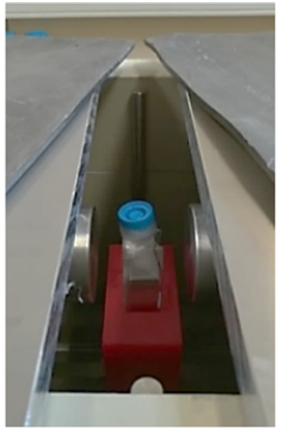

Fig. 7 Top: Photo of a mercury sample filled in a cell culture flask, placed between both HPGe detectors, bottom: MCNP® model positions of a point source simulated in the cell culture flask
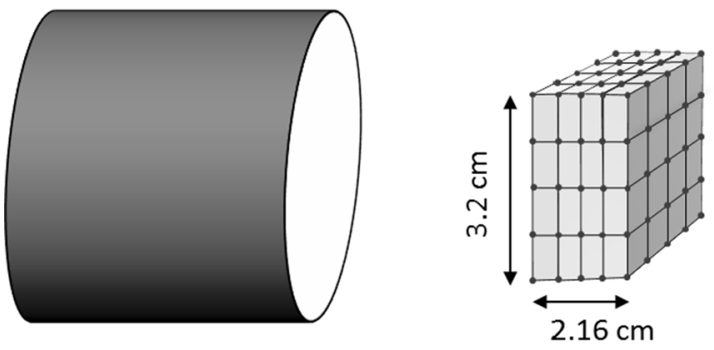

Detector 2
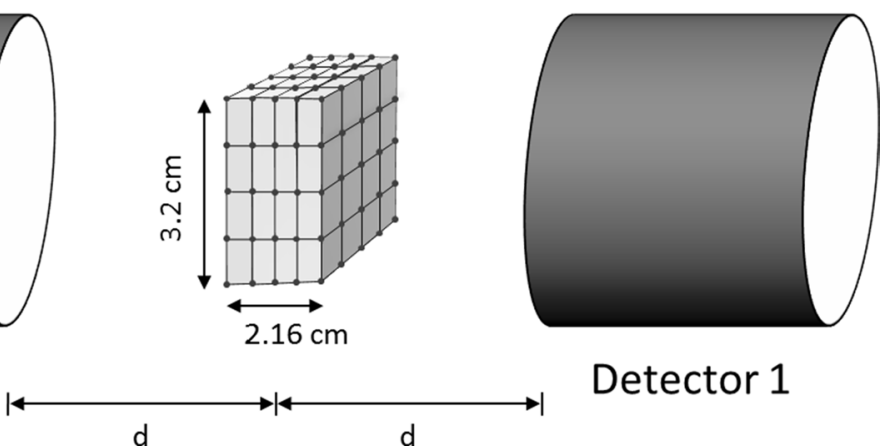

Detector 1 the evaluation of the measurements of real mercury samples in the cylindrical flask.

Figure 6 shows the simulated energy-dependent photo peak efficiency curves at position 9 for the sum spectrum using the cylindrical sample flask filled with air and mercury. The left graph marked in red shows the energy-dependent efficiency in the mercury matrix with a maximum around the $661.67 \mathrm{keV}$ emission line, thus illustrating that ${ }^{137+} \mathrm{Cs}$ is well suited as reference nuclide for these measurements. This efficiency curve for mercury (red squares) is compared to the efficiency for the same geometry in air, without mercury (blue circles), in the right graph. The effect of mercury shielding causes a vastly reduced photo peak efficiency, especially at emission energies below $500 \mathrm{keV}$. Simulated photo peak efficiencies were practically zero for emission energies below $150 \mathrm{keV}$. These results confirm that a direct gamma-spectrometric determination of e.g. ${ }^{241} \mathrm{Am}$ is not possible in a mercury matrix and the given measurement setup.

The point of the lowest photo peak efficiency for the cell culture flask was determined analogue to the cylindrical flask. Due to the irregular shape of the cell culture 
Fig. 8 Simulated photo peak efficiencies of the $661.67 \mathrm{keV}$ emission line at different positions in the mercury-filled cell culture flask for the sum spectrum of both detectors, top: point of the maximum photo peak efficiency, bottom: point of the lowest photo peak efficiency
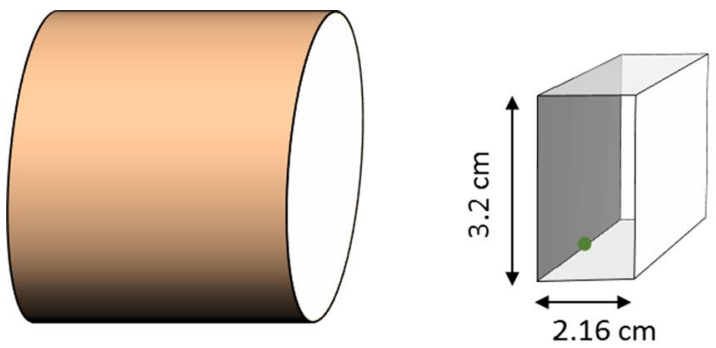

Detector 2

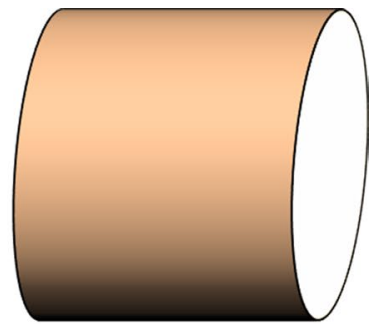

Detector 1

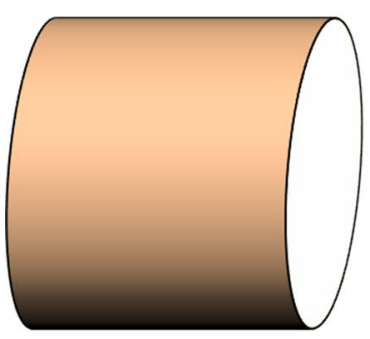

Detector 2 d

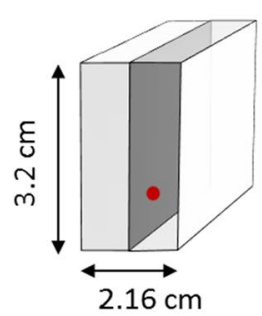

d

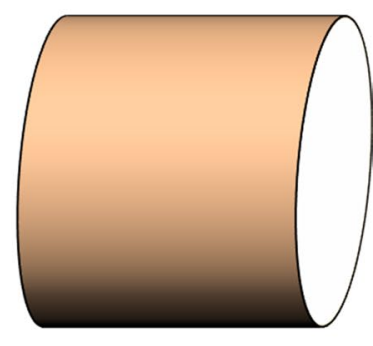

Detector 1

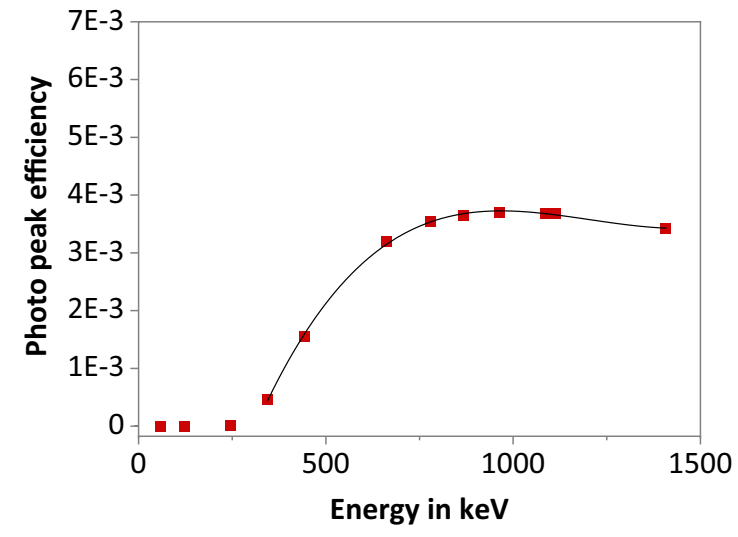

Fig. 9 Simulated photo peak efficiency curves for the sum spectrum at the point of the lowest photo peak efficiency determined for the $661.67 \mathrm{keV}$ emission line in the cell culture flask, left: efficiency

flask, the ${ }^{137+}$ Cs point source was simulated in 125 different positions inside the $25 \mathrm{~mL}$ mercury sample at a distance $d$ between each detector and the middle of the sample of $5 \mathrm{~cm}$, as shown in Fig. 7.

The general trends of the photo peak efficiencies were similar to the cylindrical sample flask (all values are in the Supplementary Information). The highest photo peak efficiency for the measurement with a single detector was found in front of the respective detector while the lowest efficiency was found at the opposite side of the sample. For the sum

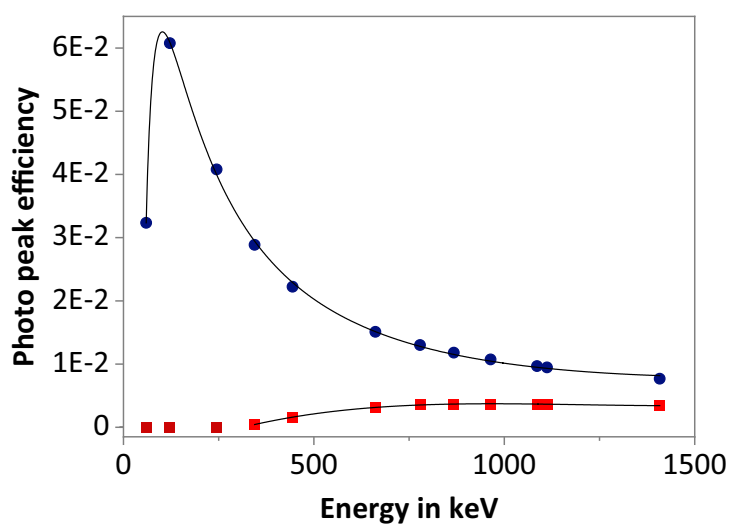

curve in mercury matrix (red squares, right: comparison of the efficiency curves in mercury (red squares) and air (blue circles)

spectrum of both detectors, however, the highest photo peak efficiency of $1.15 \cdot 10^{-2}$ was found at the bottom of the sample due the low sample thickness and reduced shielding effects at this point, towards detector 2 which has the higher relative efficiency of both detectors (compare Fig. 8). The lowest photo peak efficiency was found inside the mercury matrix in the middle between both detectors. An efficiency of $3.20 \cdot 10^{-3}$ was detected at this point for the $661.67 \mathrm{keV}$ emission line and was used in the further evaluation of measurements of real mercury samples. 


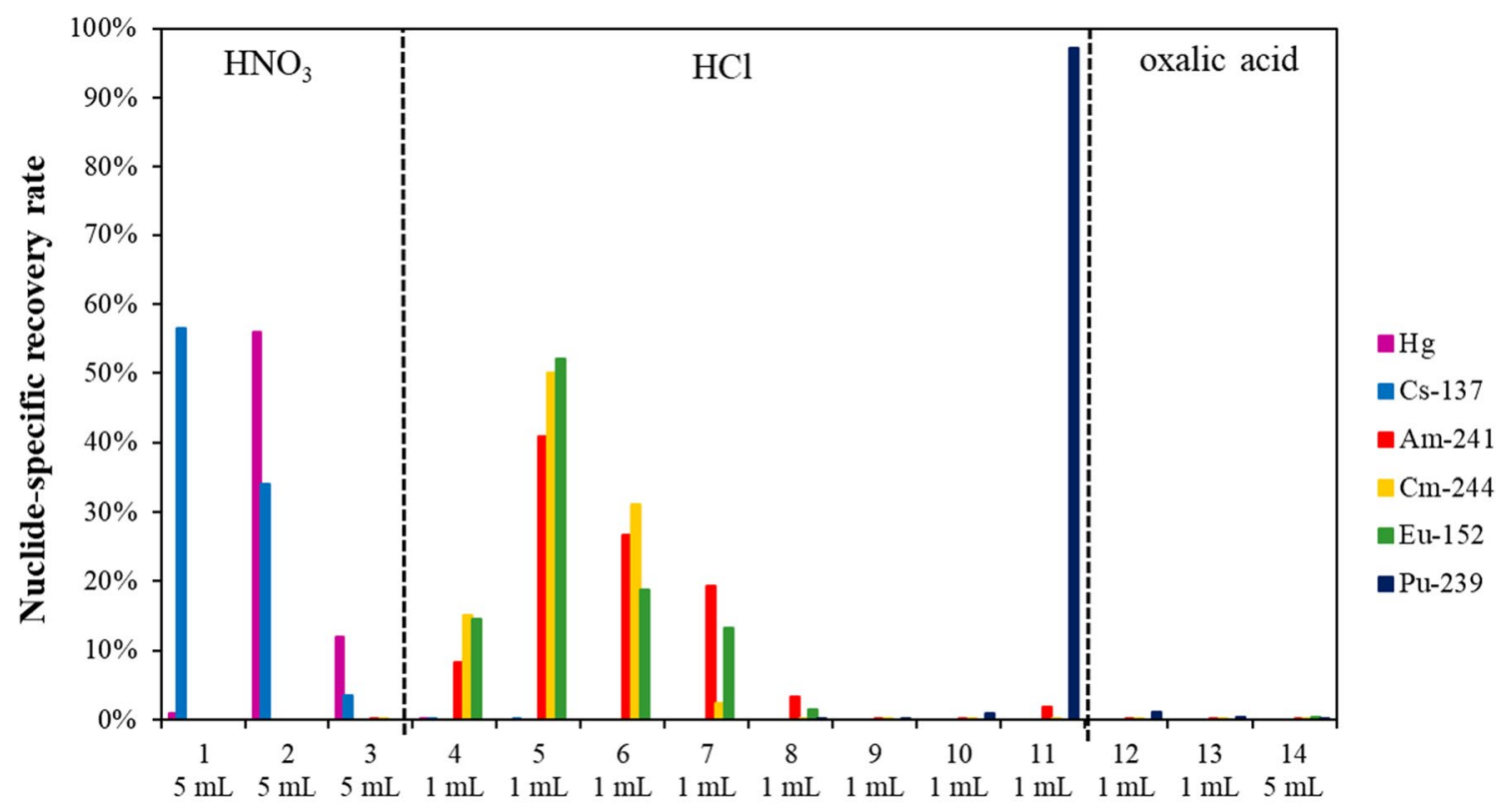

\section{Fraction no., Volume}

Fig. 10 Extraction chromatography results. TRU resin from Triskem was used for the separation of mercury from the alpha-emitting radionuclides and subsequent separation of plutonium from americium, curium and europium

The energy-dependent photo peak efficiency curves of the sum spectrum in mercury (red squares) and air (blue circles) were determined for this point of lowest photo peak efficiency for the $661.67 \mathrm{keV}$ emission line (Fig. 9). Both curves show similar trends compared to the cylindrical sample flask, with only slightly different efficiency values. As the cell culture flask is thicker than the custom-made cylindrical flask, the efficiency is reduced due to higher shielding effects of mercury.

\section{Characterisation and decontamination of mercury samples}

Contaminated mercury samples from the decommissioning of a hot cell facility in Jülich were first characterised radiologically with a specially developed wet-chemical characterisation approach. Aliquots from the mercury samples were first dissolved in nitric acid and radiochemical separation was then performed by extraction chromatography. The TRU resin from Triskem was found suitable for the separation of mercury and the different radionuclides. This resin is impregnated with a combination of the two extractants tributyl phosphate (TBP) and octyl(phenyl)- $N, N$-diisobutylcarbamoylmethylphospine oxide (CMPO) [42, 43].

An example of this separation is illustrated in Fig. 10. The chromatography column was loaded with the sample in $4 \mathrm{~mol} \mathrm{~L}^{-1}$ nitric acid and afterwards eluted with $4 \mathrm{~mol} \mathrm{~L}^{-1}$ nitric acid, $4 \mathrm{~mol} \mathrm{~L}^{-1}$ hydrochloric acid and $0.1 \mathrm{~mol} \mathrm{~L}^{-1}$ oxalic acid. Three main fractions were collected: the first fraction (mainly nitric acid) containing mercury, caesium and strontium, the second fraction (mainly hydrochloric acid) containing americium, curium and europium and the third fraction (mainly oxalic acid) containing plutonium. This separation enables an adequate characterisation of the alpha-emitting nuclides after removal of the mercury. Furthermore, the separation between americium and plutonium is crucial for the subsequent alpha-spectrometric characterisation due to a potential overlap of the respective emission lines. Radiological analyses were then performed by gamma and alpha spectrometry as well as LSC measurements.

The radioactive contaminations were mostly detected in a separate, inhomogeneous phase floating on top of the bulk mercury in the form of oil, sludge and solid particles. The elemental mercury itself was found to be significantly decontaminated by mechanically separating it from the floating radioactive residues. Well-established decontamination techniques, e.g. vacuum distillation and washing of mercury, were found to lead to a further purification of the bulk elemental mercury. Both of these methods have long been applied even on a technical scale for the purification of conventional mercury wastes. For the purpose of this work, mercury was mainly decontaminated by washing, that is by contacting the elemental mercury with a washing agent in a separatory funnel and subsequent separation of the phases. Suitable washing agents were found to be both nitric acid and hydrochloric acid or even water. The 
Table 3 Characterisation results from radioactive residues of a radioactively contaminated mercury sample in Jülich determined by gamma and alpha spectrometry and LSC measurements

\begin{tabular}{lll}
\hline Nuclide & Activity in $\mathrm{kBq} \mathrm{g}^{-1}$ & Percentage (\%) \\
\hline${ }^{137+} \mathrm{Cs}$ & 50 & 68.6 \\
${ }^{90+} \mathrm{Sr}$ & 21 & 28.8 \\
${ }^{154} \mathrm{Eu}$ & 0.1 & 0.1 \\
${ }^{241} \mathrm{Am}$ & 0.6 & 0.8 \\
${ }^{239 / 240} \mathrm{Pu}$ & 0.3 & 0.4 \\
${ }^{244} \mathrm{Cm}$ & 0.5 & 0.7 \\
${ }^{242} \mathrm{Cm}$ & 0.4 & 0.5 \\
\hline
\end{tabular}

This experimentally determined nuclide vector was used in the following gamma-spectrometric measurements of the mercury samples.

The mercury samples from the decommissioning of the hot cell facility in Jülich were measured on the HPGe detector setup after decontamination. In a first feasibility study one sample was decontaminated prior to the measurements and measured in the cylindrical sample flask. These results were compared to an analogue measurement with the commercially available cell culture flask for comparison. The respective decision threshold (allowing a conclusion whether the nuclide is present in the sample) and detection limit (the smallest amount of the nuclide that can be quantified) were
Table 4 Experimentally determined nuclide vector of mercury samples in Jülich and possible clearance values for mercury samples

\begin{tabular}{lrlll}
\hline $\begin{array}{l}\text { Experimentally } \\
\text { determined nuclide } \\
\text { vector of } \mathrm{Hg}\end{array}$ & \begin{tabular}{l} 
Clearance value in $\mathrm{Bq} \mathrm{g}^{-1}[40]$ \\
\cline { 3 - 5 } \begin{tabular}{l} 
samples \\
\cline { 3 - 5 }
\end{tabular}
\end{tabular} & $\begin{array}{l}\text { Unrestricted clearance of } \\
\text { solid and liquid materials }\end{array}$ & $\begin{array}{l}\text { Specific clearance of } \\
\text { metal waste for recy- } \\
\text { cling }\end{array}$ & $\begin{array}{l}\text { Specific clearance of solid } \\
\text { materials for disposal on } \\
\text { landfills }\end{array}$ \\
\hline${ }^{137+} \mathrm{Cs}$ & $68.6 \%$ & 0.1 & 0.6 & 10 \\
${ }^{90+} \mathrm{Sr}$ & $28.8 \%$ & 1 & 9 & 6 \\
${ }^{154} \mathrm{Eu}$ & $0.1 \%$ & 0.1 & 0.5 & 10 \\
${ }^{241} \mathrm{Am}$ & $0.8 \%$ & 0.1 & 0.3 & 1 \\
${ }^{239 / 240} \mathrm{Pu}$ & $0.4 \%$ & 0.1 & 0.2 & 1 \\
${ }^{244} \mathrm{Cm}$ & $0.7 \%$ & 1 & 0.5 & 10 \\
${ }^{242} \mathrm{Cm}$ & $0.5 \%$ & 10 & 5 & 80 \\
\hline
\end{tabular}

successful decontamination was confirmed by destructive radiological analysis of mercury samples. Samples were therefore analysed radiologically after decontamination by partial dissolution and subsequent low-level LSC measurement as well as gamma spectrometry. The results proved that large parts of the mercury could potentially be released into reuse or conventional hazardous waste disposal after an adequate decontamination and clearance procedure. The decontamination and subsequent analysis proved that the radioactive contaminations were not distributed in the elemental mercury itself but were located in the floating (oily and solid) residues as well as the phase boundary between both phases. A decontamination of the elemental mercury thus proved to be straightforward and very effective. These promising results of the decontaminated mercury samples were afterwards examined with our gamma spectrometry setup to prove the suitability of our approach for the measurement of elemental mercury samples without the need for a wet-chemical analysis, thus avoiding the dissolution of large amounts of mercury and the production of substantial amounts of secondary wastes.

The characterisation results of the residues from one mercury sample are summarised in Table 3 . In the analysed samples, ${ }^{137+} \mathrm{Cs}$ was found to be the main radionuclide, followed by ${ }^{90+} \mathrm{Sr}$, and lower amounts of ${ }^{154} \mathrm{Eu}$ and actinides. determined for each measurement according to DIN ISO 11929 [41] to evaluate the sensitivity of the measurement procedure. The activity of ${ }^{137+}$ Cs was determined for each sample with the photo peak efficiency that was determined by MCNP® simulations as described above. The activities of the other radionuclides in the mercury samples $\left({ }^{90+} \mathrm{Sr}\right.$, ${ }^{154} \mathrm{Eu},{ }^{241} \mathrm{Am},{ }^{239 / 240} \mathrm{Pu},{ }^{244} \mathrm{Cm},{ }^{242} \mathrm{Cm}$ ) were calculated by their experimentally determined ratios in the mercury samples, as given in Table 4. The sum formula for clearance (calculated as $\sum\left(\mathrm{C}_{\mathrm{i}} / \mathrm{FG}_{\mathrm{i}}\right)$ with $\mathrm{C}_{\mathrm{i}}$ as the activity of a nuclide in the sample and $\mathrm{FG}_{\mathrm{i}}$ as the clearance value for the respective nuclide given in the German radiation protection ordinance [40]) was considered for each sample and all activities were reviewed in the context of a possible clearance of the samples.

Possible clearance values for mercury from the German radiation protection ordinance are included in Table 4 [40]. As it is not yet clear which values would be applicable for the clearance of mercury, the lowest value, i.e. the value for unrestricted clearance, is considered here for the evaluation of the results.

The measurement results of two mercury samples, one in the cylindrical flask and one in the cell culture flask, are compared in Table 5. Both samples were prepared in a 
Table 5 Measurement results of two similarly decontaminated mercury samples in the cylindrical flask and the cell culture flask for $d=5 \mathrm{~cm}$ and a live time of $80,000 \mathrm{~s}$

\begin{tabular}{lll}
\hline & Cylindrical flask & Cell culture flask \\
\hline Mercury sample identifier & $\mathrm{Hg} 31.1$ & $\mathrm{Hg} 31.2$ \\
${ }^{137+} \mathrm{Cs}$ photo peak efficiency & $6.07 \cdot 10^{-3}$ & $3.20 \cdot 10^{-3}$ \\
${ }^{137+} \mathrm{Cs}$ decision threshold in $\mathrm{Bq} \mathrm{g}^{-1}$ & $8.43 \cdot 10^{-4}$ & $2.03 \cdot 10^{-3}$ \\
${ }^{137+} \mathrm{Cs}$ detection limit in Bq g & & $4.19 \cdot 10^{-3}$ \\
${ }^{-1}$ & $1.74 \cdot 10^{-3}$ & $\leq 4.19 \cdot 10^{-3}$ \\
Uncest estimate of ${ }^{137+} \mathrm{Cs}$ activity in $\mathrm{Bq} \mathrm{g}^{-1}$ & $\leq 1.74 \cdot 10^{-3}$ & $\pm 2.04 \cdot 10^{-5}$ \\
Sum formula for clearance $\sum\left(\mathrm{C}_{\mathrm{i}} / \mathrm{FG}_{\mathrm{i}}\right)$ & $\pm 1.08 \cdot 10^{-4}$ & $4.75 \cdot 10^{-2}$ \\
Sufficient sensitivity? & $1.97 \cdot 10^{-2}$ & Yes \\
Activities $<$ clearance values ? & Yes & Yes \\
$\sum\left(\mathrm{C}_{\mathrm{i}} / \mathrm{FG}_{\mathrm{i}}\right)<1$ ? & Yes & Yes \\
\hline
\end{tabular}

similar way: they were taken from a mercury waste quota in Jülich by mechanical separation of the mercury from impurities and filled into the respective sample flask for measurement. The measurements were performed on the HPGe detector setup at a distance $d$ between detector and the middle of the sample of $5 \mathrm{~cm}$ and a live time of $80,000 \mathrm{~s}$. The net peak area of the $661.67 \mathrm{keV}$ emission line of ${ }^{137+} \mathrm{Cs}$ from the sum spectrum of both detectors was evaluated and the results are displayed in Table 5. The uncertainty of the ${ }^{137+}$ Cs activity was calculated by Gaussian error propagation considering the uncertainties of the measured count rate, of the simulated photo peak efficiency and the uncertainty of the emission probability of the ${ }^{137+}$ Cs decay. For the very low activities, these uncertainties are very significant due to the high uncertainty of the measured count rates.

For both sample flasks, the decision threshold and the detection limit for ${ }^{137+} \mathrm{Cs}$ are sufficiently low for an adequate determination of ${ }^{137+} \mathrm{Cs}$ in the context of a clearance measurement. The value for unrestricted clearance of solid and liquid material for ${ }^{137+} \mathrm{Cs}$ is $0.1 \mathrm{~Bq} \mathrm{~g}^{-1}$. The achieved detection limits for ${ }^{137+} \mathrm{Cs}$ of $1.74 \cdot 10^{-3}$ and $4.19 \cdot 10^{-3} \mathrm{~Bq} \mathrm{~g}^{-1}$, respectively, are well below $10 \%$ of the clearance value and thus the measurement procedure can be considered sufficiently sensitive for this measurement purpose. No ${ }^{137+} \mathrm{Cs}$ activity above the detection limit was found in the samples. The best estimate for the ${ }^{137+}$ Cs activity and the derived activities of the other nuclides were all well below the values for unrestricted clearance. The conditions of the sum formula for clearance were also met and therefore a clearance of these samples is considered possible under these conditions.

The necessary efficiency can be achieved with both sample flasks in spite of the shielding properties of the mercury sample. Although the thicker mercury layer in the cell culture flask compared to the geometry-optimised cylindrical flask leads to a significantly reduced photo peak efficiency, the sensitivity of both measurements was sufficient and allowed an assessment on the possibility of a clearance of these samples. Both samples were found to be sufficiently decontaminated and should be suitable for a clearance procedure of the mercury. The commercially available cell culture flask was chosen for further decision-making measurements of decontaminated mercury samples due to better availability as well as easier and safer handling.

A larger number of mercury waste quotas were decontaminated to show the feasibility and practical applicability of this concept for a variety of samples. Well-known techniques for the purification of conventional mercury are vacuum distillation as well as washing procedures. Both methods, always in combination with a mechanical separation of the impurities, were also applied in this work and were found to be suitable for the decontamination of radioactively contaminated mercury samples.

Due to the nature of the contaminations that were mostly floating on top of the bulk elemental mercury, the most significant decontamination was already achieved by mechanical separation of the bulk elemental mercury. Further purification, if necessary, was then mainly performed by washing with water, nitric acid or hydrochloric acid. Although the general feasibility of mercury decontamination by vacuum distillation (at pressures of around 4 mbar and temperatures of around $200{ }^{\circ} \mathrm{C}$ ) had been shown, this method was not applied here on a larger number of samples as it is more time-consuming and therefore less efficient than the washing techniques.

The results of decontamination and decision-making measurements for clearance are summarised in Table 6. All samples were measured at a distance $d$ between detector and the middle of the sample of $5 \mathrm{~cm}$ in the aforementioned cell culture flasks (except for the sample no. $\mathrm{Hg} \mathrm{31.2,} \mathrm{which} \mathrm{was}$ filled into the cylindrical flask and is discussed here for comparison). The decision threshold and detection limit were determined from each measurement as well as the maximum activity of ${ }^{137+} \mathrm{Cs}$ and the other nuclides from the experimentally determined nuclide vector of the samples, including the result of the sum formula for clearance (cf. Table 6).

The conservative value of the photo peak efficiency of $3.20 \cdot 10^{-3}$ for ${ }^{137+}$ Cs that was determined by MCNP was 


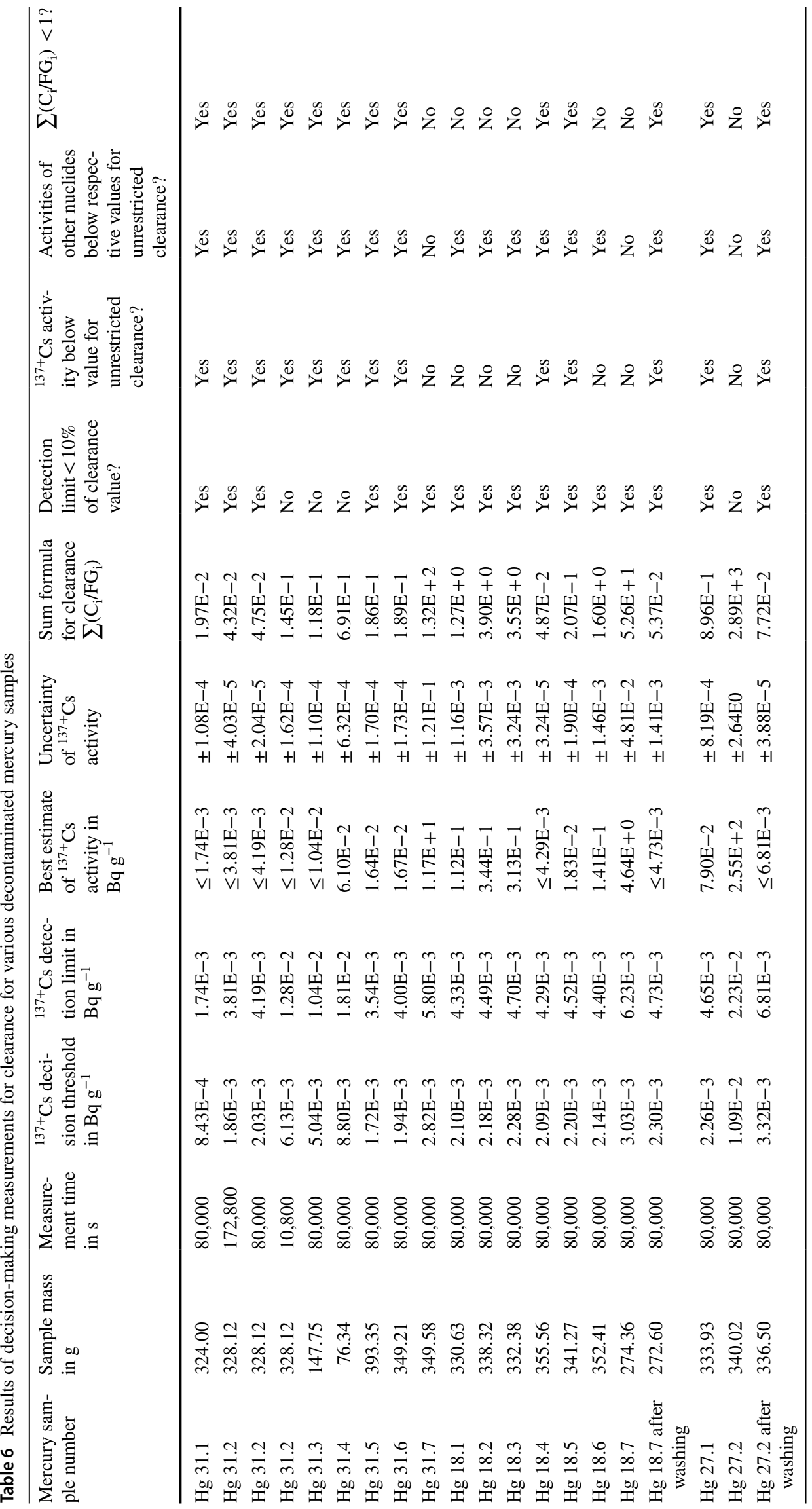


applied for all measurements that are discussed here (except for sample no. $\mathrm{Hg} 31.2$, which was measured in the cylindrical flask). This efficiency was determined for $25 \mathrm{~mL}$ of mercury. The measurements listed in Table 6, however, comprise different samples with varying volumes of mercury as well as different measurement times and different decontamination approaches. A variety of different samples and conditions was applied for the measurements to analyse the influence on the measurement results. Important parameters for such measurements especially include the sample mass and measurement time necessary to achieve a sufficient sensitivity (i.e. sufficiently low detection limits) of the measurements. These experimental conditions for potential clearance measurements were determined by this systematic parameter variation.

The first measurements displayed in Table 6, sample no.

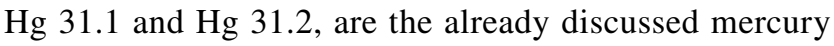
aliquots that were mechanically separated from a mercury sample and filled into a cylindrical sample flask and a cell culture flask, respectively. Both fulfilled all conditions necessary for a clearance of these samples as already discussed in the previous section. For the sample no. 31.2, the standard measurement time of $80,000 \mathrm{~s}$ was varied to determine its influence on the sensitivity of the measurement. The measurement time of only 10,800 s, however, led to a significantly reduced sensitivity - as well as the measurements of the following two samples no. 31.3 and 31.4 with reduced sample masses (147.74 and $76.34 \mathrm{~g}$ of mercury), that also led to a reduced sensitivity of the measurement. The determined photopeak efficiency for the measurement of $3.20 \cdot 10^{-3}$ for ${ }^{137+} \mathrm{Cs}$ is extremely conservative for these two measurements, as the sample mass is much lower than for the calibration. The aim of these measurements is not an adequate activity determination, yet a variation of the measured sample mass to evaluate the appropriate measurement conditions. From these results, a measurement time of 80,000 s and a sample mass of around $320-390 \mathrm{~g}$ of mercury were found to be appropriate for this specific measurement geometry and yield an adequate sensitivity for a potential clearance procedure.

Further mercury aliquots that could be sufficiently decontaminated just by mechanical separation of the elemental mercury from the radioactive contaminations were the samples $\mathrm{Hg} 31.5,31.6,18.4,18.5$ and 27.1. They originate from different mercury waste quotas from the decommissioning of hot cell facilities in Jülich but were all easily decontaminated and considered suitable for a clearance procedure (compare measurement results in Table 6).

The remaining aliquots from mercury waste in Jülich $(\mathrm{Hg}$ $31.7,18.1,18.2,18.3$ and 18.6, 18.7 and 27.2) could not be sufficiently decontaminated by mechanical separation, illustrating the need for a subsequent decontamination step. These samples were mainly removed from the surface of mercury waste quotas and thus contained more radioactive contaminations than the bulk mercury. For samples 18.7 and 27.2, the results of a second decontamination technique, i.e. washing of the samples with nitric acid (Hg 18.7) and water (Hg 27.2) are displayed in Table 6. The decontaminated samples are considered suitable for a clearance procedure, as no activity of ${ }^{137+} \mathrm{Cs}$ above the detection limit of the measurement was detected after the decontamination by washing of the samples.

Overall, the general (theoretical) feasibility of clearance measurements for mercury for two different measurement geometries as well as the practical applicability on a range of different decontaminated waste samples from nuclear facilities in Jülich was demonstrated within this work.

\section{Conclusions}

In this work, a new concept for the decontamination and possible clearance of mercury from nuclear facilities was developed as part of a disposal concept for radioactively contaminated mercury waste. A gamma-spectrometric measurement setup was developed and simulated by MCNP® to determine the photo peak efficiency in the measurement of mercury samples under conservative assumptions. Decisionmaking measurements were performed with decontaminated mercury samples from the decommissioning of a hot cell facility in Jülich to evaluate the suitability of the clearance procedure in accordance with the German radiation protection ordinance. It was shown that the necessary sensitivity for clearance measurements was achieved with this setup and the measured radionuclide inventory was below the most conservative clearance values. The measurement procedure is therefore considered suitable and the clearance of large parts of the decontaminated mercury could be possible. The easy gamma-spectrometric measurement avoids the need for a wet-chemical analysis, thus avoiding the dissolution of large amounts of mercury and the production of substantial amounts of secondary wastes.

Supplementary Information The online version contains supplementary material available at https://doi.org/10.1007/s10967-021-07840-7.

Acknowledgements This work was performed in the framework of the joint research project PROMETEUS ("PROcess of radioactive MErcury Treatment under EU Safety-standards"). The project was funded by the German Federal Ministry of Education and Research (Bundesministerium für Bildung und Forschung, BMBF) under Grant agreement numbers $15 \mathrm{~S} 9266 \mathrm{~A}-\mathrm{B}$. The responsibility for the content lies within the authors.

Funding Open Access funding enabled and organized by Projekt DEAL. 
Open Access This article is licensed under a Creative Commons Attribution 4.0 International License, which permits use, sharing, adaptation, distribution and reproduction in any medium or format, as long as you give appropriate credit to the original author(s) and the source, provide a link to the Creative Commons licence, and indicate if changes were made. The images or other third party material in this article are included in the article's Creative Commons licence, unless indicated otherwise in a credit line to the material. If material is not included in the article's Creative Commons licence and your intended use is not permitted by statutory regulation or exceeds the permitted use, you will need to obtain permission directly from the copyright holder. To view a copy of this licence, visit http://creativecommons.org/licenses/by/4.0/.

\section{References}

1. Werner CJ et al. (2018) MCNP 6.2 Release Notes. Report LA-UR18-20808, Los Alamos National Laboratory, Los Alamos, Indiana

2. Werner (editor) CJ (2017) MCNP Users Manual—code version 6.2. Report LA-UR-17-29981, Los Alamos National Laboratory, Los Alamos, Indiana

3. Management of Problematic Waste and Material Generated During the Decommissioning of Nuclear Facilities (2006) Technical Reports Series 441. International Atomic Energy Agency (IAEA), Vienna, Austria

4. Shcherbina N, Klaß L, Deissmann G, Bosbach D (2017) Research for the safe management of nuclear wastes: The special case of 'problematic' radioactive waste streams. In: Bruhns H (ed) Frühjahrstagung des Arbeitskreises Energie in der Deutschen Physikalischen Gesellschaft, Münster, 27-29 March 2017 2017. Arbeitskreis Energie (AKE) in der DPG, Bad Honnef, pp 121-134

5. Lierse von Gostomski C, Erntl H, Jörg G, Remmert A, Stöwer W, Bach F-W, Jendras M, Kutlu I, Wilk P, Nerlich K-D, Artinger R, Plank W, Schöner P, Blesnki H-J, Berthold M (2010) Entsorgung von Beryllium/Berylliumoxid und Cadmium aus Forschungsreaktoren. Technische Universität München, Fakultät für Chemie, Lehrstuhl für Radiochemie, München, Germany

6. Klaß L, Wilden A, Modolo G, Hirsch M, Kettler J, Havenith A (2020) Fachlicher Schlussbericht des BMBF Forschungsvorhabens Verbundprojekt „PROcess of radioactive MErcury Treatment under EU Safety-standards (PROMETEUS)“, Förderkennzeichen 15S9266A-B. Jülich, Germany

7. New Developments and Improvements in Processing of 'Problematic' Radioactive Waste (2007) International Atomic Energy Agency, Vienna

8. Brennecke P (2015) Anforderungen an endzulagernde radioaktive Abfälle (Endlagerungsbedingungen, Stand: Dezember 2014). Salzgitter, Germany

9. Berg HP, Brennecke PW, Thomauske BR (1987) The German konrad repository project. Progr Nucl Energ 20(3):255-307. https://doi.org/10.1016/0149-1970(87)90008-4

10. Wang J, Feng X, Anderso WNC, Xing Y, Shang L (2012) Remediation of mercury contaminated sites - a review. J Hazard Mat 221-222:1-18

11. Rodríguez O, Padilla I, Tayibi H, López-Delgado A (2012) Concerns on liquid mercury and mercury-containing wastes: A review of the treatment technologies for the safe storage. J Environ Manage 101:197-205. https://doi.org/10.1016/j.jenvman.2012.02.013

12. Liu Y, Adewuyi YG (2016) A review on removal of elemental mercury from flue gas using advanced oxidation process: chemistry and process. Chem Eng Res Des 112:199-250. https://doi. org/10.1016/j.cherd.2016.06.024

13. Conde A, de Damborenea J, Arenas MA, López FA, Alguacil FJ, López-Delgado A (2007) Literature review concerning corrosion problems in mercury and stabilisation of liquid Hg. Status Report, MERSADE (Mercury Safe Deposit) Project, Spain

14. Global Mercury Assessment 2018 (2019) http://library.arcticport al.org/1954/1/Global_Mercury_Assessment_2018.pdf

15. Bunker ME (1983) Early reactors-from Fermi's water boiler to novel power prototypes. Los Alamos Sci 7:124-131

16. Waltar AE, Reynolds AB (1981) Fast breeder reactors. Pergamon Press, New York

17. Smith RR, Cissel DW (1978) Fast reactor operation in the United States. In: International symposium on design, construction, and operating experience of demonstration liquid metal fast breeder reactor, Bologna, Italy, pp 10-14

18. Status of liquid metal cooled fast breeder reactors (1985) Technical reports series / International Atomic Energy Agency, vol 246. International Atomic Energy Agency (IAEA), Vienna, Austria

19. Morrison BH, Blanco RE (1956) The HERMEX process for metal decontamination by mercury processing. Oak Ridge National Laboratory, Oak Ridge, Tennessee

20. Dean OC, Sturch E, Morrison BH, Blanco RE (1957) Status of the HERMEX process. Oak Ridge National Laboratory, Oak Ridge, Tennessee

21. Jensen SE, Ølgaard PL (1995) Description of the Prototype Fast Reactor at Dounreay. Ris $\varnothing$ National Laboratory, Roskilde, Denmark

22. Compere AL, Griffith WL, Huxtable WP, Wilson DF (1998) Strategies for the cost-effective treatment of Oak Ridge legacy wastes. Oak Ridge National Laboratory, Oak Ridge, Tennessee

23. Brooks SC, Southworth GR (2011) History of mercury use and environmental contamination at the Oak Ridge Y-12 Plant. Environ Pollut 159(1):219-228. https://doi.org/10.1016/j.envpol.2010. 09.009

24. Acosta LN, Flexer V (2018) A first assessment on the scale-up possibilities of different electrochemical techniques for lithium isotopic enrichment. Ind Eng Chem Res 57(33):11399-11413. https://doi.org/10.1021/acs.iecr.8b01640

25. Giegerich T, Day C (2013) The THESEUS facility-a test environment for the Torus exhaust vacuum pumping system of a fusion power plant. In: 2013 Institute of Electrical and Electronics Engineers (IEEE) 25th symposium on fusion engineering (SOFE), San Francisco, California, pp 10-14

26. Giegerich T, Day C, Jäger M (2017) Mercury ring pump proofof-principle testing in the THESEUS facility. Fusion Eng Des 124:809-813. https://doi.org/10.1016/j.fusengdes.2017.03.119

27. Coffin DO (1982) A tritium-compatible high-vacuum pumping system. J Vac Sci Technol 20(4):1126-1131. https://doi.org/10. $1116 / 1.571586$

28. Alonso JR (1998) Status Report on the spallation neutron source (SNS) project. In: 6th European Particle Accelerator Conference, Stockholm, Sweden, pp 22-26

29. Odano N, Johnson JO, Harrington RM, DeVore JR (1998) Shielding and activation analyses in support of the spallation neutron source (SNS) ES\&H requirements. In: 1998 ANS radiation protection and shielding division topical meeting, Nashville, Tennessee, pp 19-23

30. Mansur LK, Haines JR (2006) Status of the Spallation Neutron Source with focus on target materials. J Nucl Mater 356(1):1-15. https://doi.org/10.1016/j.jnucmat.2006.05.031

31. Haines JR, McManamy TJ, Gabriel TA, Battle RE, Chipley KK, Crabtree JA, Jacobs LL, Lousteau DC, Rennich MJ, Riemer BW (2014) Spallation neutron source target station design, development, and commissioning. Nucl Instrum Methods Phys Res A 764:94-115. https://doi.org/10.1016/j.nima.2014.03.068

32. Gabriel TA, Barnes JM, Charlton LA, DiStefano J, Farrell K, Haines J, Johnson JO, Mansur LK, Pawel SJ, Siman-Tov M, Taleyarkhan R, Wendel MW, McManamy TJ, Rennich MJ (1997) Overview of Target Systems for the Spallation Neutron Source. 
In: international workshop on cold moderators for pulsed neutron sources, Argonne, Illinois

33. Mansur LK, Gabriel TA, Haines JR, Lousteau DC (2001) R\&D for the Spallation Neutron Source mercury target. J Nucl Mater 296(1):1-16. https://doi.org/10.1016/S0022-3115(01)00560-8

34. Kókai Z, Török S, Zagyvai P, Kiselev D, Moormann R, Börcsök E, Zanini L, Takibayev A, Muhrer G, Bevilacqua R, Janik J (2018) Comparison of different target material options for the European Spallation Source based on certain aspects related to the final disposal. Nucl Instrum Methods Phys Res B 416(1):1-8. https:// doi.org/10.1016/j.nimb.2017.11.027

35. Naoe T, Kogawa H, Wakui T, Haga K, Teshigawara M, Kinoshita $\mathrm{H}$, Takada H, Futakawa M (2016) Cavitation damage prediction for the JSNS mercury target vessel. J Nucl Mater 468:313-320. https://doi.org/10.1016/j.jnucmat.2015.08.035

36. Tietze-Jaensch H (2000) JESSICA, the ESS-like target/reflector and advanced cold moderator test facility. Phys B 276-278:102103. https://doi.org/10.1016/S0921-4526(99)01350-2

37. Stelzer H, Hinssen H-K, Nueninghoff K, Soltner H, Bayer N, Matzerath T, Pohl C (2003) Wolters J JESSICA, the test facility for an advanced cold moderator system for ESS. In: 11th International Conference on Nuclear Engineering (ICONE-11), Tokyo, Japan, pp 20-23

38. Wagner R, Bräutigam W, Filges D, Ullmaier H (2000) The project "European Spallation Neutron Source (ESS)": status of R\&D programme. Phys B 276:38-44. https://doi.org/10.1016/S09214526(99)01271-5
39. Klaß L, Ritz P, Hirsch M, Havenith A, Kettler J, Wilden A, Daniels N, Modolo G (2019) Measurement concept for a possible clearance of mercury waste from nuclear facilities. Paper presented at the Waste Management Symposium 2019 (WM 2019), Phoenix, Arizona, pp 3-7

40. Verordnung zur weiteren Modernisierung des Strahlenschutzrechts (2018) Berlin, Germany

41. DIN Deutsches Institut für Normung e.V. (2011) DIN ISO 11929: Bestimmung der charakteristischen Grenzen (Erkennungsgrenze, Nachweisgrenze und Grenzen des Vertrauensbereichs) bei Messungen ionisierender Strahlung Grundlagen und Anwendungen (ISO 11929:2010). DIN ISO 11929, vol DIN ISO 11929. DIN Deutsches Institut für Normung e.V., Berlin

42. Extraction chromatography-Technical Documentation. TrisKem International, Bruz, France

43. Horwitz EP, Chiarizia R, Dietz ML, Diamond H, Nelson DM (1993) Separation and preconcentration of actinides from acidic media by extraction chromatography. Anal Chim Acta 281(2):361-372. https://doi.org/10.1016/0003-2670(93)85194-O

Publisher's Note Springer Nature remains neutral with regard to jurisdictional claims in published maps and institutional affiliations. 